\title{
Well Marginated Nodule
}

National Cancer Institute

\section{Source}

National Cancer Institute. Well Marginated Nodule. NCI Thesaurus. Code C157663.

The nodule margin can be outlined with your pencil. Spiculated margins are not necessarily poorly marginated; ground glass nodules may be well marg inated. 